\title{
Environmentally Benign Syntheses and Characterization of 4- Aryldihydropyrimidin-2(1H)-ones
}

\author{
Syed Salman Shafqat ${ }^{1}$, Amir Azam Khan ${ }^{1}$, Misbahul Ain Khan ${ }^{2}$, Nicholas Kuan Hoo Tien ${ }^{1}$, Mohd Syahmi Jamaludin ${ }^{1}$, \\ Pang Suh $\mathrm{Cem}^{3}$ \\ ${ }^{1}$ Department of Mechanical and Manufacturing Engineering, Faculty of Engineering, Universiti Malaysia Sarawak (UNIMAS), 94300 \\ Kota Samarahan, Sarawak, Malaysia. \\ ${ }^{2}$ Department of Chemistry, The Islamia University of Bahawalpur, Pakistan. \\ ${ }^{3}$ Department of chemistry, Faculty of Resource Science \& Technology Universiti Malaysia Sarawak (UNIMAS), 94300 Kota \\ Samarahan, Sarawak, Malaysia.
}

\begin{abstract}
A general, simple, efficient, cost-effective and environmental benign procedure for the syntheses of 4-aryl-3,4-dihydropyrimidin-2(1H)-ones (DHPMs) has been developed. The reaction is efficiently catalysed by using various amino acids viz., glycine, L-proline, L-cysteine, leucine and tryptophan. Reactions give excellent yields under reflux conditions. The chemical structures of these compounds were identified by Fourier Transform-Infra Red Spectroscopy (FT-IR), Gas Chromatography-Mass Spectroscopy (GC-MS) and Nuclear Magnetic Resonance Spectroscopy ( ${ }^{1} \mathrm{H}$ NMR). Physical parameters such as m.p., mixed m.p. as well as TLC also helped to characterize the expected products. The progress of the reaction time and purity was checked by TLC and the products were purified by recrystallization using ethyl acetate as a solvent. The synthesized molecule has numerous biological applications as it is anti-microbial, anti-inflammatory and anti-hypertensive in character.
\end{abstract}

Key Words: Green Approach, Amino Acids, 4-Aryldihydropyrimidinone.

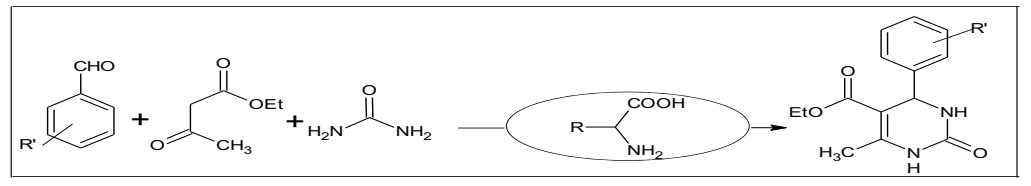

\section{Introduction}

The synthesis of dihydropyrimidinones (DHPMs) has gained importance in recent years due to structural similarities between dihydropyrimidinones and pyrimidine [1]. Pyrimidines are one of biologically important families. Pyrimidine bases such as cytosine (C), thymine $(\mathrm{T})$, are basic constituents in nucleic acids [2]. This class of heterocyclic compounds has also very important pharmaceutical activities such as antimicrobial [3], anti-inflammatory [4], antitumor [3] antihypertensive agents [5], chemical modulators, calcium channel modulators as well as melanin concentrating hormone receptor, antagonists[6], antifungal[7], as inhibitors to replicate hepatitis B, and inhibitors of specific organic acid transporters [8], [9].

In1893, Pietro Biginelli reported synthesis of 4dihydropyrimidin-2(1H)-one by cyclocondensation of ethyl acetoacetate, benzaldehyde, and urea by simply heating a mixture of these three components in the presence of acid as a catalysts under reflux conditions $[10]$. 


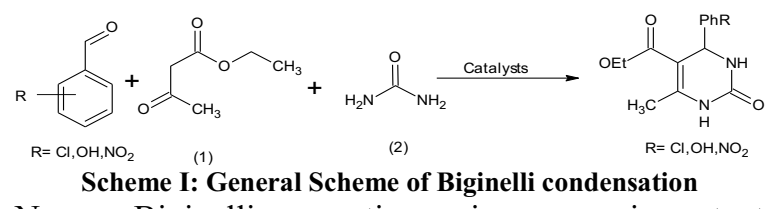

Now Biginelli reaction is an important multicomponent reaction for the preparation of biologically active dihydropyrimidinone derivatives. Usually the synthesis of 4-aryldihydropyrimidin2(1H)-ones (DHPMs) is carried out by the condensation of an aromatic aldehyde, ethyl acetoacetate, urea/thiourea in the presence of metal salts [11], [12], Bronsted and Lewis acids [13], ionic liquids [14]microwave irradiations [15] or refluxing acetic acid for few hours[16] .

Many of these classical methods, however, suffer from drastic reaction conditions, lower yields, difficult workup process, excessive use of chemicals as well as catalyst and environmental impact such as carcinogenic solvents and non-biodegradable catalysts [17]. Although a variety of methods are reported for the synthesis of DHPMs, only few examples were developed with the aim of replacing conventional toxic and polluting Bronsted and Lewis acid catalysts with efficient and green catalysts such as recyclable catalyst under solvent-free conditions[18] , amino acid catalyzed [19], [20], 21], Mesoporous SBA-15 nanoparticles[22] and Quaternary Ammonium-treated clay in water catalyzed[23]synthesis of DHPMs. Drawbacks of these classical methods and catalytic efficacy of environmental benign catalyst gave us a direction to introduce new efficient catalysts for prepration of 4aryl-3,4-dihydropyrimidin-2(1H)-ones with cost effectiveness and mild conditions with high yields.

We had earlier communicated our preliminary finding that amino acids can be efficiently used for these reactions [19]. Dihydropyrimidinone (DHPM) synthesis was carried out by using benzaldehyde and urea/thiourea.

Amino acids are also being reported as efficient catalysts in the Knoevenagel condensations, reduction, oxidation, electrophilic $\alpha$-fluorination and amination, transamidation, as well as promoter of some of the reactions [24], [25].

We are extending this Biginelli, amino acid catalyzed reaction, using some other aryl aldehydes which are now being communicated.

\section{Experimental Work}

Most of the chemicals used during the development of this environmentally benign synthesis were of laboratory grade and were used as it as. Progress of the reactions were monitored by using Silica TLC plates and UV light was used as a spot locating agent. IR were recorded on Perkins Elmer FTIR (spectrum RXI) spectrometer. Mass spectra were recorded GC-
MS Schimadzu QP2010. ${ }^{1} \mathrm{H}$ NMR spectra were recorded on and (NMR; Jeol JNM-ECA500).

\subsection{Synthesis of 4-Aryldihydropyrimidin- 2(1H)-ones:}

General Method: A reactions mixture containing $40 \mathrm{mmol}$ of aromatic aldehyde, $40 \mathrm{mmol}$ of ethyl acetoacetate, $45 \mathrm{mmol}$ of urea, $0.01 \mathrm{mmol}$ of an amino acid were dissolved in $10 \mathrm{ml}$ of ethanol. The reaction mixture was heated under reflux for two hours. The reaction mixture was work up by allowing to cool down to room temperature and was diluted with ice cold water and the precipitated product was isolated. The product was recrystallized from ethyl acetate o purify.

Four aromatic aldehydes were used by using this general procedure to syntheses four different 4-Aryldihydropyrimidin-2(1H)-ones by employing five different amino acids as catalysts.

2.1.1 By using $\boldsymbol{p}$-chlrobenzyldehyde (4): $4.5 \mathrm{~g}$ of $p$-chlrobenzyldehyde (4) was mixed with $5.2 \mathrm{~g}$ of ethyl acetoacetate (1), $4 \mathrm{~g}$ of urea (2) and $.01 \mathrm{mmol}$ of glycine in $10 \mathrm{ml}$ of ethanol. The reaction mixture was heated in reflux conditions for 2 hours. The reaction was allowed to stand to room temperature and then crushed ice was added to it, pale yellow crystals of 5Ethoxycarbonyl-6-methyl-4- $p$ -

chlorophenyldihydropyrimidin-2-one (4) were collected and recrystallized to purify the product. The product was characterized through its m.p., IR, Mass spectrum and ${ }^{1} \mathrm{H}-\mathrm{NMR}$. After this the reaction was carried out by employing few other amino acids. These products were identical in their physical and chemical characteristics to the product obtained by using glycine. The proposed reaction is presented in scheme (scheme II) and results are described in (Table 1).

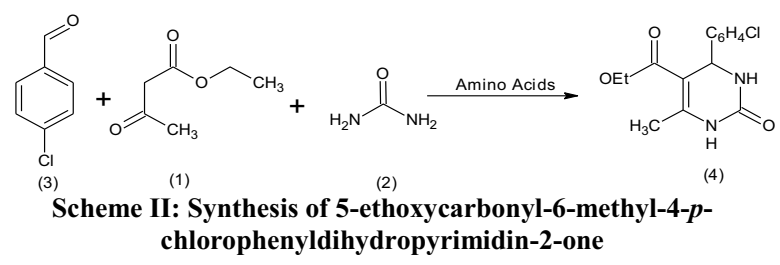

2.1.2: By using p-nitrobenzaldehyde (5): Condensation of $p$-nitrobenzaldehyde (5) with ethyl acetoacetate (1) and urea (2) was conducted by using Glycine as a catalyst as a test reaction. This reaction gave good yield of 5-Ethoxycarbonyl-6-methyl-4- $p$ nitrophenyldihydropyrimidin-2-one (6). So this reaction was carried out by employing other available amino acids. The products were characterized through m.p., IR, Mass spectrum and ${ }^{1} \mathrm{H}-\mathrm{NMR}$. The proposed reaction is presented in scheme (scheme III) and results are summarized in (Table 2). 


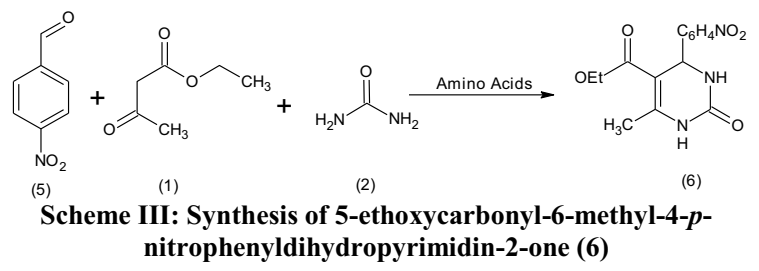

2.1.3 By using 2-hydroxybenzaldehyde (7): Condensation of 2-hydroxybenzaldehyde (7) with ethyl acetoacetate (1) and urea (2) was carried out in the presence of Glycine as catalyst using ethanol as a solvent. This reaction gave a very good yield of 5Ethoxycarbonyl-6-methyl-4-o-

hydroxyphenyldihydropyrimidin-2-one (8). The same reaction was also carried out in the presence of other available amino acids. The product (8) was characterized through its m.p., IR, Mass spectrum and ${ }^{1} \mathrm{H}-\mathrm{NMR}$ and verified its structure. The proposed reaction is presented in scheme (scheme IV) and results are summarized in (Table3).

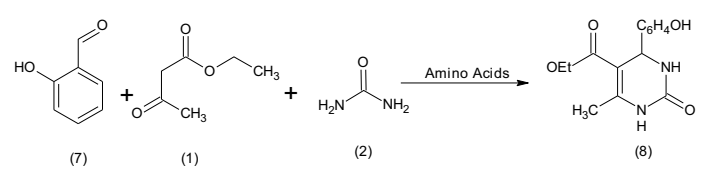

Scheme IV: Synthesis of 5-ethoxycarbonyl-6-methyl-4-ohydroxyphenyldihydropyrimidin-2-one (8)
2.1.4 By using 4-hydroxybenzaldehyde (9): Condensation of 4-hydroxybenzaldehyde (9) with ethyl acetoacetate (1) and urea (2) in the presence of Glycine gave 5-Ethoxycarbonyl-6-methyl-4- $p$ hydroxyphenyldihydropyrimidin-2-one (10). Some other amino acids were also used to prepare product (10). The product (10) was characterized through its TLC, m.p., IR, Mass spectrum and ${ }^{1} \mathrm{H}-\mathrm{NMR}$. All the products were identical in the characteristics. The proposed reaction is presented in scheme (scheme $\mathbf{V}$ ) and results are presented in (Table 4).

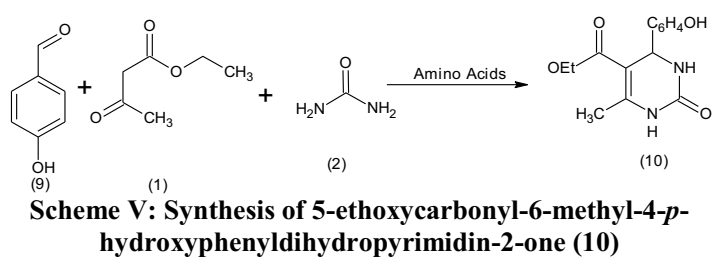

Table 1: Characterization of 5-Ethoxycarbonyl-6-methyl-p-chlorophenyldihydropyrimidin-2-one (4)

\begin{tabular}{|c|c|c|c|c|c|}
\hline Entry & Catalyst & Yield \% & $\begin{array}{c}\text { m.p. }{ }^{\circ} \mathrm{C} \\
\text { Lit }^{[26]} \\
\text { m.p210 }\end{array}$ & IR $\mathrm{cm}^{-1}$ & $\mathbf{M S}(\mathbf{m} / \mathbf{z})$ \\
\hline 1 & glycine & 92 & 207 & \multirow{5}{*}{$\begin{array}{l}3236(\mathrm{~N}-\mathrm{H}) \\
3113(\text { aro } \mathrm{C}-\mathrm{H}) \\
2985(\text { ali C-H }) \\
1710(\mathrm{C}=\mathrm{O}) \\
1646(\mathrm{C}=\mathrm{C}) \\
1461(\mathrm{C}-\mathrm{H}) \\
1281(\mathrm{C}-\mathrm{O}) \\
776(\mathrm{Cl})\end{array}$} & \\
\hline 2 & L-cysteine & 94 & 206 & & $294(\mathrm{M}+)$ \\
\hline 3 & L-proline & 95 & 208 & & $265(30 \%)$ \\
\hline 4 & $B$-alanine & 93 & 206 & & $\begin{array}{l}221(25 \%) \\
183(100 \%)\end{array}$ \\
\hline 5 & tryptophan & 90 & 205 & & \\
\hline
\end{tabular}


Table 2: Synthesis and characterization of 5-Ethoxycarbonyl-6-methyl-4-nitrophenyldihydropyrimidin-2-one (6)

\begin{tabular}{|c|c|c|c|c|c|c|}
\hline Entry & Catalyst & Yield \% & $\begin{array}{l}\text { m.p }{ }^{0} \mathrm{C} \\
\text { Lit } \\
208^{[26]}\end{array}$ & IR $\mathrm{cm}^{-1}$ & $\mathbf{M S}(\mathbf{m} / \mathbf{z})$ & ${ }^{1}$ H NMR \\
\hline 1 & glycine & 95 & 207 & & & $\begin{array}{l}\text { NMR (500MHz, CDCl3)1H } \\
8.18(2 \mathrm{H}) \mathrm{J}=9.17 \text { (d) }\end{array}$ \\
\hline 2 & L-cysteine & 96 & 208 & $\begin{array}{c}3283(\mathrm{~N}-\mathrm{H}) \\
3102(\text { aro } \mathrm{C}-\mathrm{H}) \\
2985(\text { ali C-H })\end{array}$ & $305(\mathrm{M}+)$ & $\begin{array}{l}2 \mathrm{H} 7.50(2 \mathrm{H}) \mathrm{J}=9.17(\mathrm{~d}) \\
3 \mathrm{H} 5.552(1 \mathrm{H}) \mathrm{J}=3.06(\mathrm{~d})\end{array}$ \\
\hline 3 & L-proline & 92 & 208 & $\begin{array}{c}1717(\mathrm{C}=\mathrm{O}) \\
168 \mathrm{C}=\mathrm{O})\end{array}$ & $\begin{array}{l}288(20 \%) \\
276(15 \%)\end{array}$ & $\begin{array}{l}4 \mathrm{H} 5.74(1 \mathrm{H})(\mathrm{s}) \\
5 \mathrm{H} 2.37(3 \mathrm{H})(\mathrm{s})\end{array}$ \\
\hline 4 & B-alanine & 93 & 207 & $\begin{array}{c}1642(\mathrm{C}=\mathrm{C}) \\
1502 \text { and } \\
1323(\mathrm{NO} 2)\end{array}$ & $183(100 \%)$ & $\begin{array}{l}6 \mathrm{H} 4.10(2 \mathrm{H})(\mathrm{q}) \\
7 \mathrm{H} 1.17(3 \mathrm{H}) 6.88 \\
8 \mathrm{H} 7.4159(1 \mathrm{H}) \text { incomplete }\end{array}$ \\
\hline 5 & tryptophan & 94 & 206 & $1232(\mathrm{C}-\mathrm{O})$ & & split \\
\hline
\end{tabular}

Table 3: Synthesis and characterization of 5-Ethoxycarbonyl-6-methyl-2-hydroxyphenyldihydropyrimidin-2-one (8)

\begin{tabular}{|c|c|c|c|c|c|c|}
\hline \multirow[b]{2}{*}{ Entry } & \multirow[b]{2}{*}{ Catalyst } & \multirow[b]{2}{*}{ Yield \% } & \multicolumn{3}{|l|}{$\mathrm{m} \cdot \mathrm{p}^{0} \mathrm{C}$} & \multirow[b]{2}{*}{${ }^{1} \mathrm{H}$ NMR } \\
\hline & & & $\begin{array}{c}\text { Lit } \\
265^{[26]}\end{array}$ & IR $\mathrm{cm}^{-1}$ & $\operatorname{MS}(\mathbf{m} / \mathbf{z})$ & \\
\hline 1 & glycine & 92 & 260 & $3232(\mathrm{O}-\mathrm{H})$ & & $\begin{array}{c}\text { (NMR500 MHz,DMSO-d6, } 9.35 \\
(1 \mathrm{H})(\mathrm{s})\end{array}$ \\
\hline 2 & L-cysteine & 90 & 261 & $\begin{array}{l}3220(\mathrm{~N}-\mathrm{H}) \\
3101(\text { aro C-H }) \\
2978(\text { ali C-H })\end{array}$ & $\begin{array}{l}276(\mathrm{M}+) \\
247(20 \%)\end{array}$ & $\begin{array}{c}9.12(1 \mathrm{H})(\mathrm{s}) \\
7.63(1 \mathrm{H})(\mathrm{s}) \text { incomplete splitting }\end{array}$ \\
\hline 3 & L-proline & 93 & 259 & $\begin{array}{l}1727(\mathrm{C}=\mathrm{O}) \\
1682(\mathrm{C}=\mathrm{O})\end{array}$ & $\begin{array}{l}229(30 \%) \\
183(50 \%)\end{array}$ & $\begin{array}{l}7.02(2 \mathrm{H})(\mathrm{d}) \mathrm{J}=8.41 \\
6.68(2 \mathrm{H})(\mathrm{d}) \mathrm{J}=8.41\end{array}$ \\
\hline 4 & B-alanine & 90 & 261 & $\begin{array}{l}1653(\mathrm{C}=\mathrm{C}) \\
1513(\mathrm{C}-\mathrm{H})\end{array}$ & $57(100 \%)$ & $\begin{array}{l}5.03(1 \mathrm{H})(\mathrm{d}) \\
3.97(2 \mathrm{H})(\mathrm{qss})\end{array}$ \\
\hline 5 & tryptophan & 94 & 259 & $1212(\mathrm{C}-\mathrm{O})$ & & $\begin{array}{l}2.22(3 \mathrm{H})(\mathrm{s}) \\
1.09(3 \mathrm{H})(\mathrm{t})\end{array}$ \\
\hline
\end{tabular}

Table 4: Synthesis and characterization of 5-Ethoxycarbonyl-6-methyl-4-hydroxyphenyldihydropyrimidin-2-one (10)

\begin{tabular}{|c|c|c|c|c|c|c|}
\hline Entry & Catalyst & Yield \% & $\begin{array}{c}\text { m.p }{ }^{0} \mathrm{C} \\
\text { Lit } \\
227^{[27]}\end{array}$ & IR $\mathrm{cm}^{-1}$ & MS (m/z) & ${ }^{1}$ H NMR \\
\hline 1 & glycine & 92 & 220 & $3232(\mathrm{O}-\mathrm{H})$ & & $\begin{array}{c}\text { (NMR500 MHz,DMSO-d6, } 9.35 \\
(1 \mathrm{H})(\mathrm{s})\end{array}$ \\
\hline 2 & L-cysteine & 90 & 220 & $\begin{array}{l}3220(\mathrm{~N}-\mathrm{H}) \\
3101(\text { aro } \mathrm{C}-\mathrm{H})\end{array}$ & $\begin{array}{l}276(\mathrm{M}+) \\
247(20 \%)\end{array}$ & $\begin{array}{c}9.12(1 \mathrm{H})(\mathrm{s}) \\
7.63(1 \mathrm{H})(\mathrm{s})\end{array}$ \\
\hline 3 & L-proline & 93 & 219 & $\begin{array}{l}2978(\text { ali C-H }) \\
1727(\mathrm{C}=\mathrm{O})\end{array}$ & $\begin{array}{l}229(30 \%) \\
183(50 \%)\end{array}$ & $\begin{array}{l}7.02(2 \mathrm{H})(\mathrm{d}) \mathrm{J}=8.41 \\
6.68(2 \mathrm{H})(\mathrm{d}) \mathrm{J}=8.41\end{array}$ \\
\hline 4 & B-alanine & 95 & 220 & $\begin{array}{l}1682(\mathrm{C}=\mathrm{O}) \\
1653(\mathrm{C}=\mathrm{C}) \\
1513(\mathrm{C}-\mathrm{H})\end{array}$ & $57(100 \%)$ & $\begin{array}{l}5.03(1 \mathrm{H})(\mathrm{d}) \\
3.97(2 \mathrm{H})(\mathrm{qss})\end{array}$ \\
\hline 5 & tryptophan & 91 & 222 & 1212 (C-O) & & $\begin{array}{l}2.22(3 \mathrm{H})(\mathrm{s}) \\
1.09(3 \mathrm{H})(\mathrm{t})\end{array}$ \\
\hline
\end{tabular}




\section{Results and Discussion}

In this study as part of our continued effort to develop environmental benign and new catalysis systems with a reduced environmental impact, the utility of five amino acids viz. glycine, L-proline, L-cysteine, lucien and tryptophan is explored as catalysts for the multi component synthesis of 4-aryldihydropyrimidin2(1H)-ones. All the amino acids gave promising results with high yields under reflux conditions. Initially, a model reaction was conducted by heating a mixture of $p$-chlrobenzyldehyde, ethyl acetoacetate and urea using glycine as a catalyst and excellent results were obtained. The product 5-ethoxycarbonyl6-methyl-4- $p$-chlorophenyldihydropyrimidin-2-one (4) was obtained in almost quantitative yield (92\%). Keeping in view of this successful result various other amino acids were employed for the reaction with equal success. All the product were characterized through its m.p., IR, mass spectrum and ${ }^{1} \mathrm{H}$ NMR (Table-1). The efficacy of amino acid catalysts was further tested in the synthesis of diverse 4-aryldihydropyrimidin-2(1H)-ones with comparable results (Table1-4).Plausible mechanism for the glycine -catalyzed synthesis of 4aryldihydropyrimidin-2 $(1 \mathrm{H})$-ones has been proposed (Scheme VI). The reaction may proceed through the protonation of aromatic aldehyde (A) by the amino acid which provides this proton to catalyze the reaction. Further reaction proceeds via intermediates $\mathrm{B}$ and $\mathrm{C}$ as depicted in the scheme.
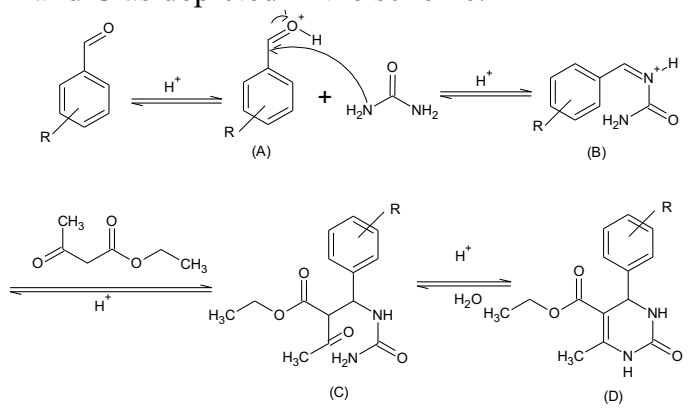

Scheme VI: Amino Acid catalyzed mechanism of Biginelli Condensation

\section{Conclusion}

In summary, amino acids were successfully employed as catalyst for the synthesis of various 4aryldihydropyrimidin-2(1H)-ones. Simple and mild reaction conditions, low cost, readily available and biodegradable catalyst are the important features of this protocol. For the present work, only a few representative aromatic aldehydes and urea were used to check the feasibility of amino acids as a catalyst in these reactions. The yields in all these reactions were comparable and the use of these catalysts can be extended to study the utilization of other aldehydes in Biginelli reactions.

\section{Acknowledgments}

We gratefully acknowledge Universiti Malaysia Sarawak (UNIMAS) to support this work under the grant No. DPI 02 (DPI08)/824/2011(08).

\section{References}

[1] I. Phucho, A. Nongpiur, S. Tumtin, R. Nongrum and R. Nongkhlaw, ChemInform 2010, 41, i.

[2] J. D. Watson and F. H. Crick, Nature 1953, 171, 737-738.

[3] M. Jalali, M. Mahdavi, H. Memarian, M. Ranjbar, M. Soleymani, A. Fassihi and D. Abedi, Research in pharmaceutical sciences 2012, 7, 243.

[4] R. H. Tale, A. H. Rodge, G. D. Hatnapure, A. P. Keche, K. M. Patil and R. P. Pawar, Medicinal Chemistry Research 2012, 21, 4252-4260.

[5] K. S. Atwal, B. N. Swanson, S. E. Unger, D. M. Floyd, S. Moreland, A. Hedberg and B. C. O'Reilly, Journal of medicinal chemistry 1991, 34, 806-811.

[6] C. O. Kappe, W. M. Fabian and M. A. Semones, Tetrahedron 1997, 53, 2803-2816.

[7] D. Duguay, M. Zamora, J. Blacquiere, F. Appoh, C. Vogels, S. Wheaton, F. Baerlocher, A. Decken and S. Westcott, Open Chemistry 2008, 6, 562-568.

[8] T. Kadre, S. R. Jetti, A. Bhatewara, P. Paliwal and S. Jain, Archives of Applied Science Research 2012, 4, 988-993.

[9] R. F. Canto, A. Bernardi, A. M. O. Battastini, D. Russowsky and V. L. Eifler-Lima, Journal of the Brazilian Chemical Society 2011, 22, 1379-1388.

[10] P. Biginelli, Gazz. Chim. Ital 1893, 23, 360-413.

[11] S. R. Narahari, B. R. Reguri, O. Gudaparthi and K. Mukkanti, Tetrahedron letters 2012, 53, 15431545 .

[12] C. Navya, D. Rajeswari, E. U. Rajitha, I. Jyothsna, K. Manasa, K. S. Kumar and A. L. Rao, International Journal of Applied Pharmaceutical Sciences 2016, 3, 301-305. 
[13] H. Kefayati, K. Rad-Moghadam, M. Zamani and S. Hosseyni, Letters in Organic Chemistry 2010, 7 , 277-282.

[14] Z. Liu, R. Ma, D. Cao and C. Liu, Molecules 2016, 21, 462 .

[15] T. Raj, B. Kaur Billing, N. Kaur and N. Singh, RSC Advances 2015, 5, 46654-46661.

[16] Faryal Chaudhry, Syed Salman Shafqat, Amir Azam Khan, and M. A. M. M. A. Khan, Synthetic Communications 2016, 46.

[17] A. R. Bhat, A. H. Shalla and R. S. Dongre, Journal of Saudi Chemical Society 2014.

[18] K. Aswin, S. S. Mansoor, K. Logaiya, P. N. Sudhan and R. N. Ahmed, Journal of Taibah University for Science 2014, 8, 236-247.

[19] Ansa Madeeha Zafar, Muhammad Naeem Khan, Muhammad Azad, Munawar Ali Munawar and Misbahul Ain Khan., Asian Journal of Chemistry 2013, 25, 3244.

[20] M. Bararjanian, S. Balalaie, B. Movassag and A. Amani, Journal of the Iranian Chemical Society 2009, 6, 436-442.

[21] S. P. Bahekar, P. B. Sarode, M. P. Wadekar and H. S. Chandak, Journal of Saudi Chemical Society 2015.

[22] Y. Sarrafi, F. Pazokie, S. Azizi, K. Alimohammadi, E. Mehrasbi and E. Chiani, Current Chemistry Letters 2014, 3, 97-102.

[23] S. Sayyahi, S. Jahanbakhshi and Z. Dehghani, Journal of Chemistry 2013, 2013.

[24] S. S. Shafqat, M. A. Khan, A. Zulkharnain, S. Hamdan, H. Rigit, and A. A. khan, Asian Journal of Chemistry 2014, 26.

[25] B. List, Tetrahedron 2002, 58, 5573-5590.

[26] S. D. Sharma, P. Gogoi and D. Konwar, Green Chemistry 2007, 9, 153-157.

[27] T. S. Jin, H. X. Wang, C. Y. Xing, X. L. Li and T. S. Li, Synthetic communications 2004, 34, 3009 3016 . 